
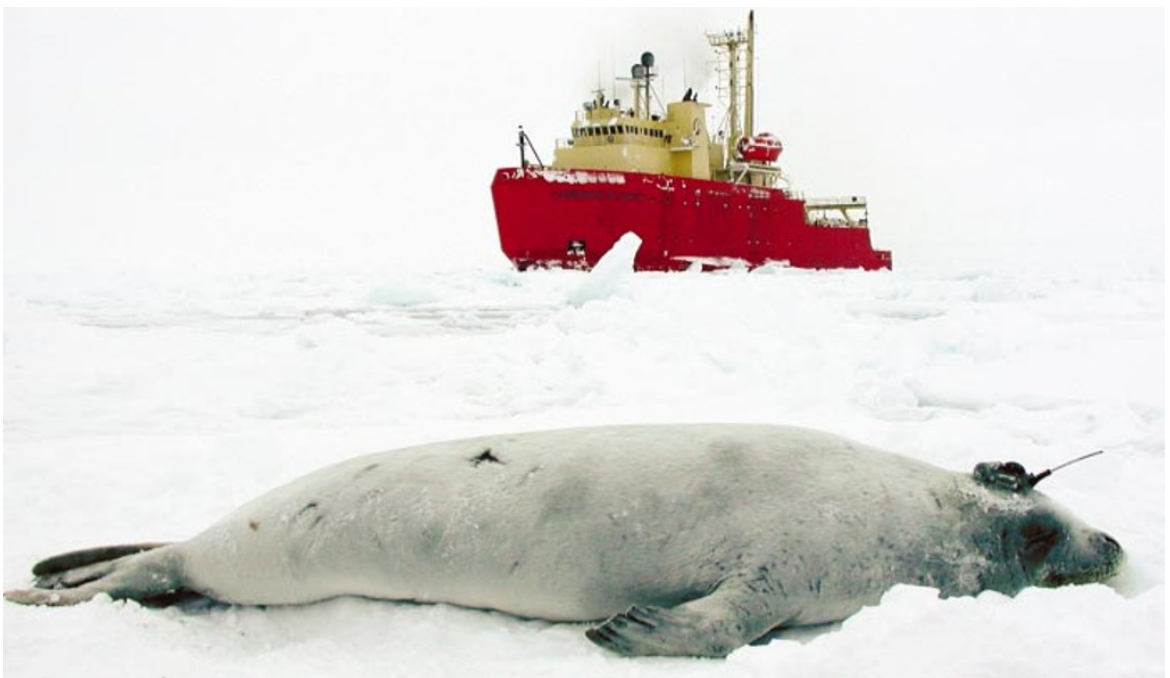

Seal the deal: the new project aims to persuade animal biologists to contribute their tagging data.

\title{
Online marine resource could soon be swimming with data
}

Jonathan Knight, Santa Cruz

Decades of raw data on the movements and diving behaviour of dolphins, whales, seals and other marine animals could soon be made available in an online database.

Leading figures in the field met last month to start laying plans for this resource. "Basically, we are trying to make a GenBank for diving data on marine mammals," says Dan Costa, a marine biologist at the University of California, Santa Cruz.

Researchers have been using time-depth recorders (TDRs) to track the movement of ocean mammals since the 1960s. TDRs adhere to an animal's back for days or weeks and then float to the surface for recovery. More recently, satellite transmitters that provide information on latitude and longitude have also become available. As they have become smaller and cheaper, the number of researchers using them has mushroomed.

Recently, tags have shown where blue whales feed and calve (B. A. Lagerquist, K. M. Stafford \& B. R. Mate Mar. Mamm. Sci. 16, 375-391; 2000) and revealed the remarkable diving ability of seals and sea lions (D. P. Costa, N. J. Gales \& M. E. Goebel Comp. Biochem. Physiol. A 129,771-783;2001).

Some of the data are already stored in public databases, but the vast majority are analysed once and then shelved. Placing them in a publicly accessible database would help biologists who want to develop a more complete picture of ocean ecosystems.

But several hurdles remain, not least convincing marine biologists to release their data. Standards for organizing data will also be needed to allow searching and comparison of different tracking and dive records.

To make a start on these issues, Costa and his postdoc Scott Shaffer gathered 45 marine biologists in Santa Cruz. Participants agreed on the utility of a data archive, but few are likely to contribute data they have not yet published.

"Investigators want to know they will have first dibs," says Bruce Mate, a whale biologist at the Hatfield Marine Science Center of Oregon State University in Newport.

So, rather than collecting tracking data as it is generated, the archive will, at least initially, be restricted to data from published studies. The resulting lag time of a year or two from data acquisition to its appearance in the archive will not be a serious problem, Mate argues, because the database's main value will be in providing access to information that is currently unavailable. Published papers contain only data summaries.

Data comparison will also be a challenge. There are several manufacturers of TDRs, and their products record essentially the same information but in different formats. Researchers may also calibrate instruments differently, setting them up to record only longer dives, for example, something that would have to be indicated in the database.

Although the archive will deal initially with marine mammals, the goal is to expand it to include other groups. Fish and seabird researchers are keen to join in, says Barbara Block, also at the University of California, Santa Cruz, who tags a range of marine vertebrates including tuna, albatrosses and turtles.

Costa's first step will be to set up a website detailing what data have been collected and where they are held. He also plans to develop a formal proposal for funding, possibly for submission to the US Office of Naval Research, which backed last month's meeting.

\section{Future funds in doubt as asteroid project wins short reprieve}

Erika Check, Washington

Following an outcry from planetary scientists, NASA has abandoned a plan to terminate radar studies of near-Earth asteroids and planets using the world's largest radio telescope. But the project's future remains uncertain, as it has only been guaranteed one more year of funding.

On 10 December, NASA told scientists working on the studies using the Arecibo Observatory in Puerto Rico that they would lose their \$550,000 funding in 2002. But just 10 days later, the agency provided $\$ 400,000$ after protests from the Planetary Society and researchers in the field.

The radar studies are supported from the same budget that finances the search for new near-Earth asteroids. But NASA is concerned that the annual total of $\$ 3.55$ million cannot cover both the discovery of new asteroids and studies of old ones.

Don Campbell, head of Arecibo's Radar Astronomy Group, claims the telescope is crucial to understanding near-Earth objects. Its radar equipment measures their shape, surface properties and velocity. "This information can be used to make substantial improvements in our ability to predict the future orbits of these objects," he says. The only comparable facility is at Goldstone, in California's Mojave Desert, but its equipment is less sensitive than that at Arecibo.

However, Tom Morgan, discipline scientist for NASA's Near-Earth Object Program, argues that space missions will prove to be "the best way to go out and answer the questions we need to answer if, God forbid, we ever have to change the orbit of one of these objects."

From 2003, the radar project will have to pass a round of peer review if it is to continue receiving funds. NASA may also try to shift the studies to the National Science Foundation, which provides most of Arecibo's \$11-million budget.

www.naic.edu

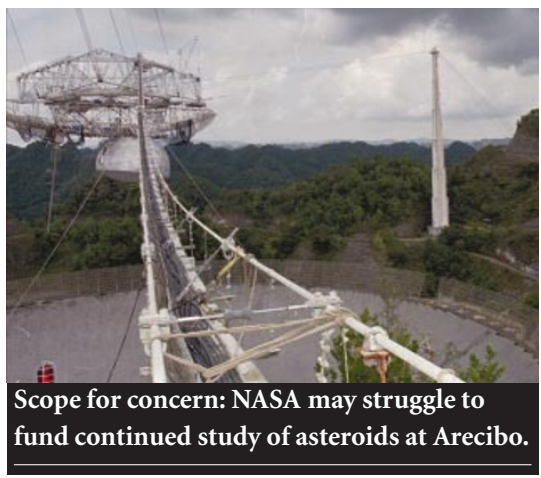

